\title{
Biogeography for Watermarking Medical Images
}

\author{
A.Umaamaheshvari ${ }^{1}$, K.Prabhakaran ${ }^{2}$, K.Thanushkodi $^{3}$ \\ ${ }^{1}$ (Assistant Professor/ECE/SSEC), ${ }^{2}$ (P.G. Student/KSOU), ${ }^{3}$ (Director/ACET)
}

\begin{abstract}
With the evolution of internet and multimedia digital watermarking is gaining momentum. In day to day life for unwanted messages few people are affected .So watermarking is essential in every part of multimedia. In the paper we are proposing a new method of watermarking based on optimization technique. Performance improvement is got from biogeography algorithm. Threshold values and embedding strength forms the important parameters for improving the visual quality of watermarked images. Independent watermark is constructed and distributed separately based on biogeography algorithm.
\end{abstract}

Keywords: biogeography, digital watermarking, Independent watermark, multimedia, threshold value

\section{INTRODUCTION}

Internet being an open source has become popular. In open source the transmitted data is corrupted, altered or stolen. Enforcing the copyright protection is a serious issue. Many methods are available for watermarking of images both in frequency domain and spatial domain. Cox et al.[1] proposed discrete cosine transform. Dugad et al.[2] proposed the discrete wavelet transform. Shieh et al .[3]proposed genetic watermarking based on transform domain. El-Khamy et al.[4] introduced the watermarking based on human visual system and wavelet based data fusion. Umaamaheshvari et al.[5] proposed a hybrid watermarking method based on daubauche 2 wavelet. Huang et al[6] worked with DCT and GA.

Many of the techniques got unsatisfactory values towards fidelity and robustness. Spatial domain techniques are having poor values. Biogeography based genetic algorithm[7] mimics the process of natural evolution. The important ROI and NROI can be classified and optimized for achieving a best solution. Appropriate locations of the cover image are identified to insert the watermark. The locations are called as populations in genetic algorithm. In biogeography algorithm deals with the distribution of species in a particular location called habitat. Habitat suitability index is a measure for the species about the temperature, rainfall, humidity, vegetation and land area. Suitability index variables are independent variables of the habitat that characterize habitability.

High HSI $=$ more number of species and static.

Low HSI $=$ less number of species and not static

Low HIS are more dynamic in their species distribution than high HSI habitats . Here low HSI denotes the low frequency components and high HSI denotes the high frequency components in an image.

Section II describes the concept of Bandlet Section III deals with Biogeography algorithm and its applicability in image watermarking. Section IV deals with the proposed method. Section V discusses with results and conclusions.

\section{BANDLET TRANSFORM}

In 2005 pennac and mallet[8] proposed a new method called bandeltization. The advantage is along the geometric flow image regularity is obtained. Redundancy is removed from the warped wavelet transform. Standard orthogonal wavelet transform is used for second generation. In a region $\Omega i$ where the geometric flow is vertically parallel. The scaling function is given by

$\mathrm{Ui}[\mathrm{k} 1, \mathrm{k} 2]=\{\mathrm{f}[\mathrm{n} 1, \mathrm{n} 2], \phi \mathrm{j}, \mathrm{jki}[\Psi \mathrm{j}, \mathrm{k} 2[\mathrm{n} 2-\mathrm{ci}[\mathrm{n} 1]]\}$

Where Ui[k1,k2] is input and $\phi \mathrm{j}, \mathrm{jki}$ is scaling function. The scaling function does not take the advantage because of geometric image regularity. The change os basis with a 1D DWT along the parameter $\mathrm{k} 1$, which computes inner products with discrete bandlet scales $2 \mathrm{i}>2 \mathrm{j}$ :

$\{\mathrm{f}[\mathrm{n} 1, \mathrm{n} 2], \Psi 1, \mathrm{k} 1[\mathrm{n} 1] \Psi \mathrm{j}, \mathrm{k} 2[\mathrm{n} 2-\mathrm{ci}[\mathrm{n} 1]]\}$

When filters $(\mathrm{h}, \mathrm{g})$ applied to $\mathrm{Ui}[\mathrm{k} 1, \mathrm{k} 2]$ along the variable $\mathrm{k} 1$, with $\mathrm{k} 2$ as fixed we get1D wavelet transform. The bandeletization when applied to warped wavelet coefficients:

$\mathrm{Ui}[\mathrm{k} 1, \mathrm{k} 2]=\{\mathrm{f}[\mathrm{n} 1, \mathrm{n} 2], \Psi \mathrm{j}, \mathrm{k} 1[\mathrm{n} 1-\mathrm{ci}[\mathrm{n} 2]] \phi \mathrm{j}, \mathrm{k} 2[\mathrm{n} 2]\}$

to compute the bandlet coefficients at scales $2 \mathrm{i}>2 \mathrm{j}$ :

f[n1,n2], $\Psi \mathrm{j}, \mathrm{k} 1[\mathrm{n} 1-\mathrm{ci}[\mathrm{n} 2]] \Psi 1, \mathrm{p} 2[\mathrm{n} 2]]\}$ 
within each region bandletization is computed and it avoids overlapping and does not create any boundary problems. It does not affect the image at all since the work is done in the warped coefficients only.

\section{BIOGEPGRAPHY OPTIMIZATION}

3.1Migration

In this part we discuss how optimization is done using biogeography in discrete domain.

Consider a problem to have a candidate solutions as vector of integers. Good solutions are considered to be habitats with a high HSI. Poor solutions are considered to be low HSI. HSI is the fitness function. Fitness function is based on peak signal to noise ratio and normalized correlation coefficient.

Fitness value $=\mathrm{PSNR}+\alpha \mathrm{NC}$

Fitness value $=\alpha \mathrm{NC}+$ PSNR

In equation (4) the fitness value increases with $\alpha$ value rather than PSNR.

3.2. Fitness function

Defines how to fit the chromosomes in the search space.

3.3. Selection and crossover

It is based on the survival of the fittest mechanism.based on the high fitness value chromosomes are selected for generating more offspring.

3.4Mutation

The offspring are subjected to mutation i.e a bit is flipped by changing 0 to 1 and 1 to 0 with a small probability.

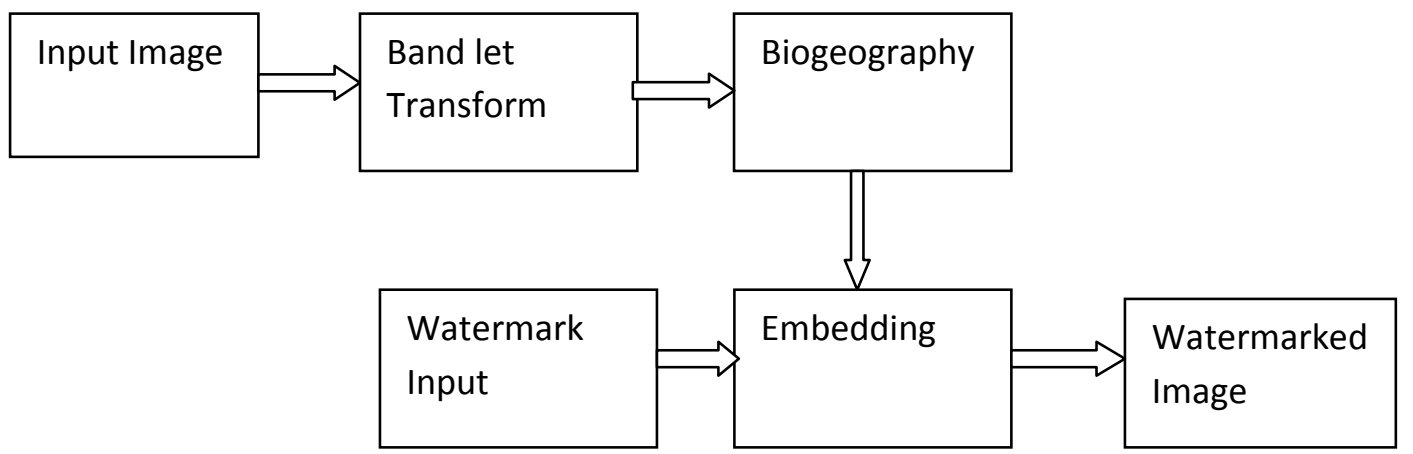

Figure 3.1 Block Diagram of the Proposed Method

3.5 Embedding algorithm

i) Start the process by getting the original file

ii)Accept the threshold percentage from the user.

iii)Choose the suitability index where to embed the watermark. Here watermark embedding is divided into lower and higher fields.

$\mathrm{L}^{*}=\mathrm{L}+\mathrm{a} * \mathrm{~W}_{\mathrm{A}}$

$\mathrm{W}_{\mathrm{A}}$ is coefficient of watermark A.L* is low coefficient of DWT .

High frequency coefficient and mid frequency coefficient forms the best segmentation by building the quadtrees.

The optimal geometric flow is computed and bandeletization is done to get bandlet coefficient.

$\mathrm{H}^{*}=\mathrm{H}+\mathrm{a} * \mathrm{~W}_{\mathrm{B}}$

$\mathrm{W}_{\mathrm{B}}$ is the coefficient of the watermark.H is bandlet coefficient and $\mathrm{H}^{*}$ is a bandlet

coefficient which embed the watermark.

iv)Initialize the first generation by reading the characters from the input file

v)Initialize generation count to zero, $\mathrm{N}$ to 0

vi)do crossover operation with best suitable index value and increment the count

vii)then Mutation() is performed

viii)finally Fitness() function is calculated

ix)Sort the obtained values.

$\mathrm{x})$ Copy the first ten values of the present generation to the next generation

xi)Go to step 6 if generation count is less than maxgen

xii)Add the values of final generation to final key text file.

xiii)End process 
3.6 Extraction algorithm

Generally the extraction process is the inverse process of embedding

i)accept the input image file.

ii)In low frequency we use direct method as $\mathrm{W}_{\mathrm{A}}{ }^{\prime}=\left(\mathrm{L}^{\prime}-\mathrm{L}\right) / \mathrm{a}$

In the high frequency we need bandletization to extract the watermark

$\mathrm{W}_{\mathrm{B}}{ }^{\prime}=\left(\mathrm{H}^{\prime}-\mathrm{H}\right) / \mathrm{a}$

\section{CONCLUSION}

This section deals with the comparative study of the various inputs and the corresponding outputs. The output of the proposed method is compared with other methods. The screen shots are shown below for CT image.

TABLE I PERFORMANCE VALUES FOR CT IMAGES

\begin{tabular}{|c|c|c|}
\hline PSNR & MSE & \multicolumn{2}{|c|}{ SSIM } \\
\hline 64.0309 & 0.0257 & 0.9124 \\
\hline 48.5227 & 0.9137 & 0.9058 \\
\hline 56.1408 & 0.1581 & 0.9157 \\
\hline 44.6947 & 2.2060 & 0.8905 \\
\hline 48.0655 & 1.0152 & 0.9016 \\
\hline
\end{tabular}

TABLE II PERFORMANCE VALUES FOR MRI IMAGES

\begin{tabular}{|c|c|c|}
\hline PSNR & MSE & SSIM \\
\hline 36.8532 & 13.4203 & 0.8878 \\
\hline 38.1485 & 9.9593 & 0.9098 \\
\hline 36.7808 & 13.6457 & 0.9141 \\
\hline 37.9888 & 10.3323 & 0.8880 \\
\hline 39.3461 & 7.5591 & 0.9092 \\
\hline
\end{tabular}

TABLE III PERFORMANCE VALUES FOR ULTRA IMAGES

\begin{tabular}{|c|c|c|}
\hline PSNR & MSE & SSIM \\
\hline 37.2461 & 12.2595 & 0.9023 \\
\hline 37.9901 & 10.3293 & 0.8939 \\
\hline 37.9476 & 10.4309 & 0.9236 \\
\hline 39.0785 & 8.0395 & 0.9311 \\
\hline 37.6604 & 11.1439 & 0.9193 \\
\hline
\end{tabular}

TABLE IV COMPARISON OF PROPOSED METHOD WITH OTHER EXISTING METHODS

\begin{tabular}{|c|c|c|c|c|c|c|c|}
\hline \multicolumn{2}{|c|}{ Proposed method } & \multicolumn{2}{|c|}{ Dugad method } & \multicolumn{2}{|c|}{ Dugad DMT1 } & \multicolumn{2}{|c|}{ GA dugad method } \\
\hline 七 & 64.03 & 苂 & 41.33 & 苞 & 41.18 & 苂 & 46.07 \\
\hline $\bar{\Sigma}$ & 39.34 & $\begin{array}{l}8 \\
\frac{8}{\pi} \\
\stackrel{\pi}{\oplus}\end{array}=$ & 34.67 & 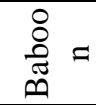 & 34.95 & $\begin{array}{l}8 \\
8 \\
\text { है } \\
\oplus\end{array}=$ & 41.87 \\
\hline$\stackrel{\text { 苞 }}{5} \ll$ & 39.07 & $\begin{array}{l}\overline{\bar{\nu}} \\
\overline{2} \\
\overline{0}\end{array}$ & 39.25 & 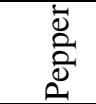 & 38.94 & 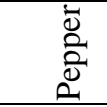 & 44.48 \\
\hline
\end{tabular}

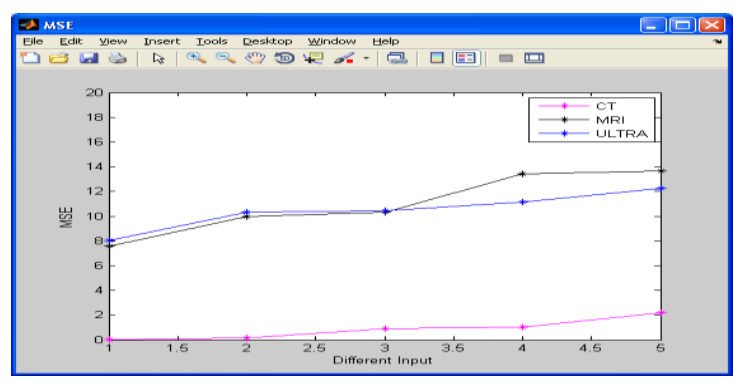

Graph 1: Different Input images vs MSE 


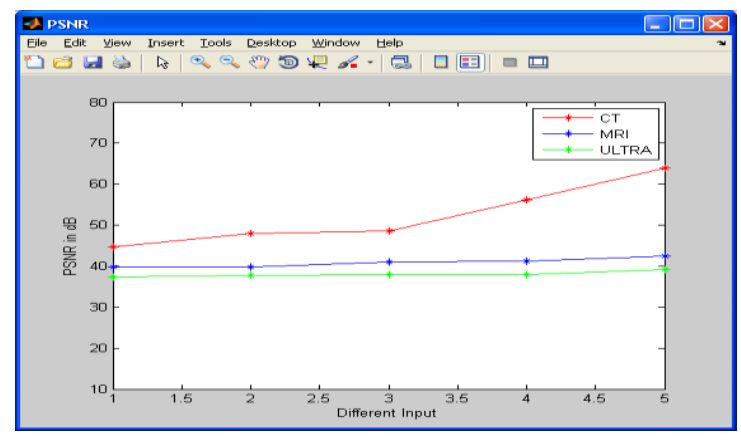

Graph 2: Different Input Images vs PSNR

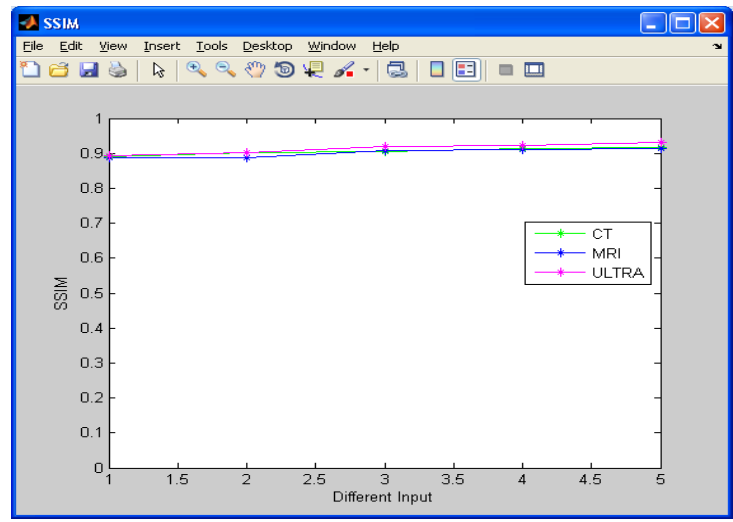

Graph 2: Different Input Images vs SSIM
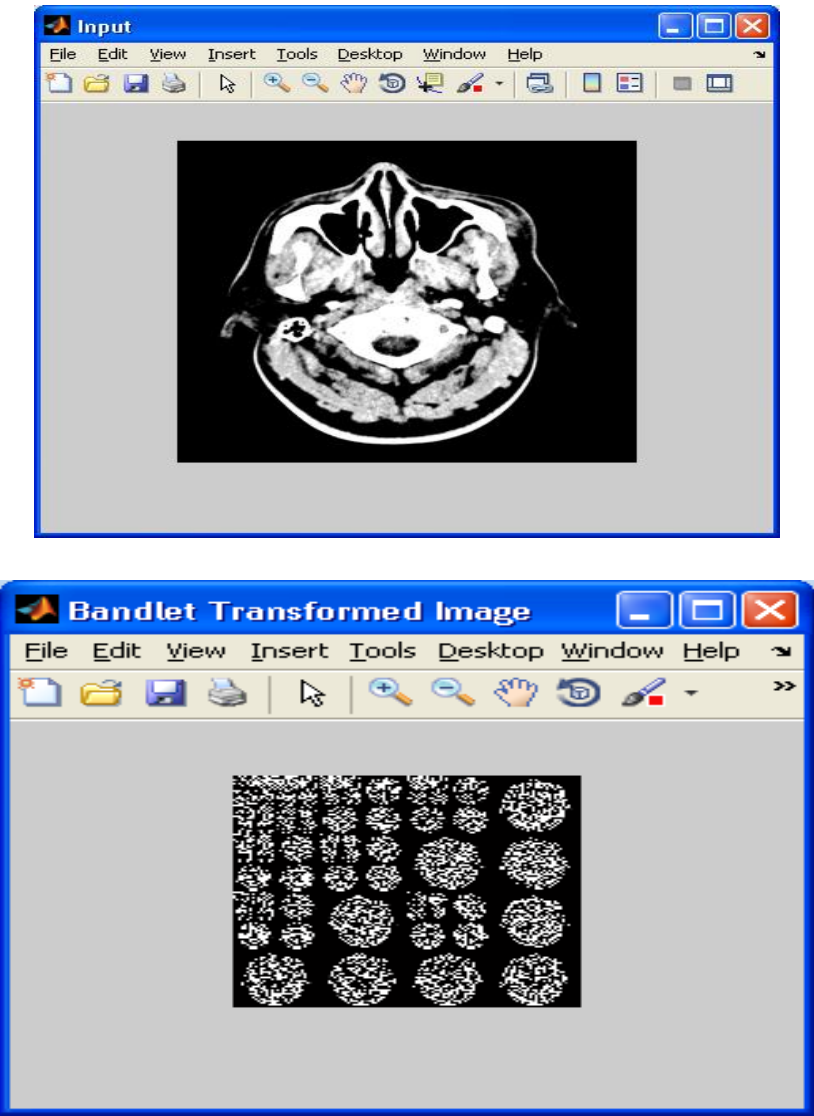


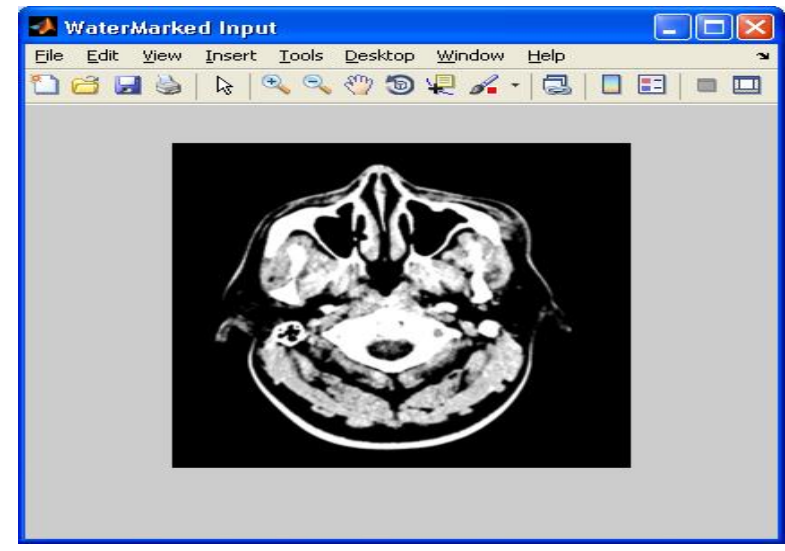

\section{Acknowledgements}

We would like to give thanks to all reference authors which we have used as well as reviewers of our paper

\section{Journal Papers:}

\section{REFERENCES}

[1]. J.J Cox,J.Kilian,F.T Leighton and T.Shamoon ,Secure spread spectrum watermarking for multimedia",IEEE Trans.Image Processes., Vol.6 no.12 , Dec 1997 , pp 1673-1687

[2]. R.Dugad,K.Ratakonda and N.Ahuja,"A new wavelet-based scheme for watermarking images",in Proc.IEEE Int. Conf.Image Processing(ICIP 1998), Vol 2 ,Oct 1998, pp.419-423

[3]. C-S Shieh, H-C Huang and F-H Wang,J-S Pan "Genetic watermarking based on transform domain technique", The journal of pattern recognition society 372004 pp 555-565

[4]. El-khamy et al. "New technique for perceptual wavelet based image watermarking",in Proc.Radio science conf (NSRC 2002),vol.1,mar.2002,pp.336-343

[5]. Umaamaheshvari.A and Thanushkodi .K High performance and effective watermarking scheme for medical images EJSR vol.67 issue. 2012.

[6]. C.H huang and j.LWu,"A watermark optimization technique based on genetic algorithms ," in Proc.SPIE-Visual Communications Image processing,vol.3971,Feb.2000,pp.516-523.

[7]. Dan Simon,"Biogeography-based optimization", in IEEE Transactions on Evolutionary Computation , Vol.12,No.6,Dec 2008,pp.702-713

[8]. Le penne and stephane mallat,"bandlet image approximation and compression", SIAM J.Multiscale modeling and simulation,2005 